\title{
Usefulness of a pharmacist outpatient service for $S-1$ adjuvant chemotherapy in patients with gastric cancer
}

\author{
MICHIO KIMURA ${ }^{1}$, MAKIKO GO $^{1}$, MINA IWAI ${ }^{1}$, EISEKI USAMI ${ }^{1}$, \\ HITOMI TERAMACHI $^{2}$ and TOMOAKI YOSHIMURA ${ }^{1}$ \\ ${ }^{1}$ Department of Pharmacy, Ogaki Municipal Hospital, Ogaki, Gifu 503-8502; ${ }^{2}$ Laboratory \\ of Clinical Pharmacy, Gifu Pharmaceutical University, Gifu 501-1196, Japan
}

Received November 15, 2016; Accepted July 4, 2017

DOI: $10.3892 / \mathrm{mco} .2017 .1337$

\begin{abstract}
S-1 adjuvant chemotherapy is an outpatient treatment for gastric cancer. To evaluate the role of the pharmacist outpatient service in increasing medication adherence and reducing adverse events associated with S-1, the present study retrospectively analyzed prescription recommendations from pharmacists to physicians and the persistence rate of S-1 adjuvant chemotherapy use in patients with gastric cancer. A total of 40 subjects who utilized the pharmacist outpatient service between November 2014 and March 2016 comprised the pharmacist group; and 94 patients who underwent S-1 adjuvant chemotherapy for gastric cancer between September 2012 and October 2014, but not as pharmacist outpatients, comprised the control group. Data on the prescription recommendations, persistence rate of S-1 adjuvant chemotherapy for 1 year and relative dose intensity were collected. The number of interventions and consultations for the pharmacist outpatient group were 40 and 644, respectively. Prescription recommendations regarding dosage, drug administration interval, and supportive therapy were provided in 62,15 and 132 cases, respectively. The prescription proposal acceptance rate was $92.5 \%$. The persistence rate of S-1 adjuvant chemotherapy for 1 year was significantly higher in the pharmacist group (82.5\%) compared with the control group (39.4\%; $\mathrm{P}<0.0001)$. The discontinuation rate due to adverse events was significantly lower in the pharmacist group (7.5\%) compared with the control group (31.9\%; $\mathrm{P}=0.0015)$. In subjects who completed $\mathrm{S}-1$ adjuvant chemotherapy, the relative dose intensities in the control and pharmacist groups were 82.9 and $84.7 \%$, respectively. In conclusion, the continued pharmaceutical intervention ensured a high persistence rate of S-1 adjuvant chemotherapy.
\end{abstract}

Correspondence to: Dr Michio Kimura, Department of Pharmacy, Ogaki Municipal Hospital, 4-86 Minaminokawa-cho, Ogaki, Gifu 503-8502, Japan

E-mail: kimkim0305nao@yahoo.co.jp

Key words: pharmacist outpatient service, S-1, adjuvant chemotherapy, gastric cancer, persistence rate, adverse events

\section{Introduction}

Tegafur-gimeracil-oteracil potassium (S-1) adjuvant chemotherapy is administered for stage II/III gastric cancer based on the results of the Adjuvant Chemotherapy Trial of TS-1 for Gastric Cancer (ACTS-GC) (1). In the stratified survival analysis of the ACTS-GC trial, S-1 administration for 1 year at $>70 \%$ of the planned dose resulted in improved survival, demonstrating the effectiveness of this treatment in patients with gastric cancer (1). Therefore, the dosage and duration of S-1 treatment may influence patient prognosis, suggesting that medication adherence and continuity of treatment are crucial. However, S-1 continuation is sometimes challenging due to adverse events (AEs) such as leukopenia, neutropenia, anorexia, nausea, vomiting, diarrhea and stomatitis (2-4). In particular, AEs such as malaise and anorexia may reduce patient quality of life (QOL), which may significantly reduce medication adherence, leading to subsequent medication rejection (4).

S-1 adjuvant chemotherapy for gastric cancer is currently used as an outpatient treatment (5). Outpatients manage their own medications and any associated AEs $(5,6)$. Therefore, it is necessary to establish a support system for cancer outpatients to provide safe and secure drug therapy.

Patients with gastric cancer with serum albumin levels $<3.5 \mathrm{~g} / \mathrm{dl}$ and creatinine clearance $<80 \mathrm{ml} / \mathrm{min}$ typically require a reduced dose or discontinuation of S-1 adjuvant chemotherapy (3). In addition, patients who discontinued S-1 or required dosage reductions due to AEs exhibited weight loss, which was due to decreased postoperative oral intake of food (3). Kawabata et al (7) reported that decreases in body mass index (BMI) during treatment may affect treatment continuity. Therefore, decreased BMI is a useful indicator for designing timely and appropriate patient guidance and prescription design support systems during S-1 adjuvant chemotherapy.

For cancer chemotherapy, hospital pharmacists in medical teams are part of a pharmacist outpatient service, and such services have improved the quality of medical care and patient QOL (8-15). However, few facilities have offered pharmacist outpatient services to patients undergoing monotherapy with oral anti-cancer agents prior to examination by a physician. Therefore, reports on the usefulness of these services are limited $(10,14)$. 
A pharmacist outpatient service (pharmacist interviews before medical examinations) for patients undergoing S-1 adjuvant chemotherapy was launched at Ogaki Municipal Hospital (Ogaki-shi, Japan) in November 2014. In the present study, the effect of this service on the persistence rate of S-1 adjuvant chemotherapy over the course of a year was assessed.

\section{Patients and methods}

Study population. Between September 2012 and March 2016, the records of patients undergoing S-1 adjuvant chemotherapy for gastric cancer were evaluated. Initially, 146 subjects were included. The pharmacist outpatient service group (PG) included 40 subjects who attended the pharmacist outpatient service for S-1 adjuvant chemotherapy for gastric cancer between November 2014 and March 2016, whose records were examined retrospectively. As a control group (CG), the doctor and pharmacy service records of 94 subjects who received S-1 adjuvant chemotherapy for gastric cancer between September 2012 and October 2015 were examined retrospectively. For the $\mathrm{CG}$, pharmacist guidance was not performed. In the present study, the CG and PG targeted subjects who started and completed S-1 postoperative adjuvant chemotherapy between the respective periods, and patients for whom outpatient pharmacists were introduced partway through their treatment were excluded from the study. Additionally, those who were transferred to another hospital during the treatment period were excluded. Oncology pharmacists were responsible for validation of patients' conditions. Patient characteristics of the two groups are presented in Table I. Personal information was protected in the aggregated data. This study received approval from the Institutional Review Board of Ogaki Municipal Hospital (no. 20150303-5), and all patients provided informed consent.

Pharmacist outpatient service. A flowchart of the pharmacist outpatient service is presented in Fig. 1. The pharmacist outpatient service was practiced on weekdays between the $h$ of 08:15 and 17:15 between November 2014 and March 2016. On the first visit, oncology pharmacists, certified by the Japanese Society of Pharmaceutical Health Care and Sciences, provided guidance to patients after a treatment plan including the therapeutic agent and dose was formulated. If treatment plan changes were desired, then inquiries with the treating physician were required. From the second visit onwards, following blood collection, pharmacists interviewed patients in the outpatient drug administration guidance room. During these interviews, adherence status was ascertained, and AEs resulting from the S-1 therapy were monitored (16). Additionally, pharmacy service records were created, prescription recommendations including those related to dosage and drug administration were issued, and supportive care (drug therapy for AEs such as nausea and diarrhea) was provided. An S-1 management table template was used to monitor AEs as described previously (16).

During medical examinations, physicians utilized the pharmacy service records (prescription proposal and AE monitoring results). While at home, patients were able to seek medical advice from pharmacists via telephone consultation during the pharmacist outpatient service opening times.
$S-1$ adjuvant chemotherapy. The minimum S-1 dose prior to attending the outpatient service was $60 \mathrm{mg} / \mathrm{day}$. The therapy protocol during the outpatient service was as follows: For 1 cycle of therapy, S-1 was administered twice daily, after morning and evening meals, for 4 weeks [80 mg/day for $<1.25 \mathrm{~m}^{2}$ body surface area (BSA); $100 \mathrm{mg} /$ day for $1.25-1.5 \mathrm{~m}^{2}$ $\mathrm{BSA}$; and $120 \mathrm{mg} /$ day for $\geq 1.5 \mathrm{~m}^{2} \mathrm{BSA}$ ], followed by a 2 -week washout period. This administration regimen was continued for a year. BSA was calculated as follows:

$$
\text { BSA }\left(\mathrm{m}^{2}\right)=\text { body weight }{ }^{0.444}(\mathrm{~kg}) \mathrm{x} \mathrm{height}^{0.663}(\mathrm{~cm}) \mathrm{x} 0.008883
$$

Data collection. Data on prescription recommendations (prescription dose, administration interval and supportive therapy) were retrieved from the drug management guidance records of the PG. In addition, the prescription proposal acceptance rate was calculated. The persistence rate of S-1 adjuvant chemotherapy over the course of a year and the reasons for discontinuation due to AEs were extracted from electronic charts. The AEs were retrospectively compared between the CG and PG. Data regarding specific AEs were extracted from the electronic charts and pharmacy service records. The severity of AEs was classified according to the Common Terminology Criteria for Adverse Events, version 4.0 (17). For subjects who completed S-1 adjuvant chemotherapy, the relative dose intensities (RDIs) of the CG and PG were compared. RDI is an index for evaluating the therapeutic intensity of the actual dose against the standard dose as follows:

RDI $(\%)=$ dose intensity (DI) calculated from the actual dose/DI of the standard dose $\mathrm{x} 100$.

DI represents the chemotherapy drug dose per unit time (week) as follows:

DI $\left(\mathrm{mg} / \mathrm{m}^{2} /\right.$ week $)=$ total dose $\left(\mathrm{mg} / \mathrm{m}^{2}\right) /$ time of treatment (week).

Statistical analysis. An F test was performed to compare the PG and CG. The Student's t or Welch's t-tests were used to analyze patient characteristics (Table I). A $\chi^{2}$ test was used to compare rates between the groups (data depicted in the PG and CG). One-way analysis of variance was conducted to determine the significance of differences in RDIs between the groups. All statistical analyses were performed using JMP 8 software (SAS Institute Inc., Cary, NC, USA). For all statistical tests, $\mathrm{P}<0.05$ was considered to indicate a statistically significant difference.

\section{Results}

Operational performance of the pharmacist outpatient service (prescription recommendations). The patient characteristics are summarized in Table I. Details of the prescription recommendations issued by the pharmacist outpatient service as well as the prescription proposal acceptance rates, between November 2014 and March 2016, are presented in Table II. Supportive therapy was recommended when there was a need to reduce AEs in order to continue S-1 treatment. The majority 
Table I. Patient characteristics.

\begin{tabular}{|c|c|c|c|}
\hline Characteristic & CG & PG & P-value \\
\hline Number of patients & 94 & 40 & \\
\hline \multicolumn{4}{|l|}{ Age, years } \\
\hline Median (range) & $68(37-83)$ & $71(47-83)$ & 0.1997 \\
\hline \multicolumn{4}{|l|}{ Sex, n } \\
\hline Male:female & $63: 31$ & 29:11 & 0.3398 \\
\hline \multicolumn{4}{|c|}{ Body surface area, $\mathrm{m}^{2}$} \\
\hline$<1.25$ & 7 & 2 & 0.8549 \\
\hline $1.25-1.50$ & 44 & 20 & \\
\hline$\geq 1.50$ & 43 & 18 & \\
\hline \multicolumn{4}{|c|}{ Disease stage (number of patients) } \\
\hline $\mathrm{Ib}$ & 1 & 0 & 0.7529 \\
\hline Ia & 15 & 4 & \\
\hline IIb & 15 & 10 & \\
\hline IIIa & 18 & 6 & \\
\hline IIIb & 20 & 9 & \\
\hline IIIc & 25 & 11 & \\
\hline \multicolumn{4}{|l|}{$\mathrm{CrCl}, \mathrm{ml} / \mathrm{min}$} \\
\hline Median (range) & $70.3(31.2-111)$ & $78.7(31.5-114)$ & 0.2260 \\
\hline \multicolumn{4}{|l|}{ BMI } \\
\hline Median (range) & $20.2(14.1-26.3)$ & $19.0(16.0-27.5)$ & 0.8595 \\
\hline \multicolumn{4}{|l|}{ Alb, g/dl } \\
\hline Median (range) & $4.1(2.9-4.6)$ & $4.1(2.9-4.5)$ & 0.8962 \\
\hline
\end{tabular}

CG, control group; PG, pharmacist outpatient clinic group; $\mathrm{CrCl}$, creatinine clearance; BMI, body mass index; Alb, albumin.

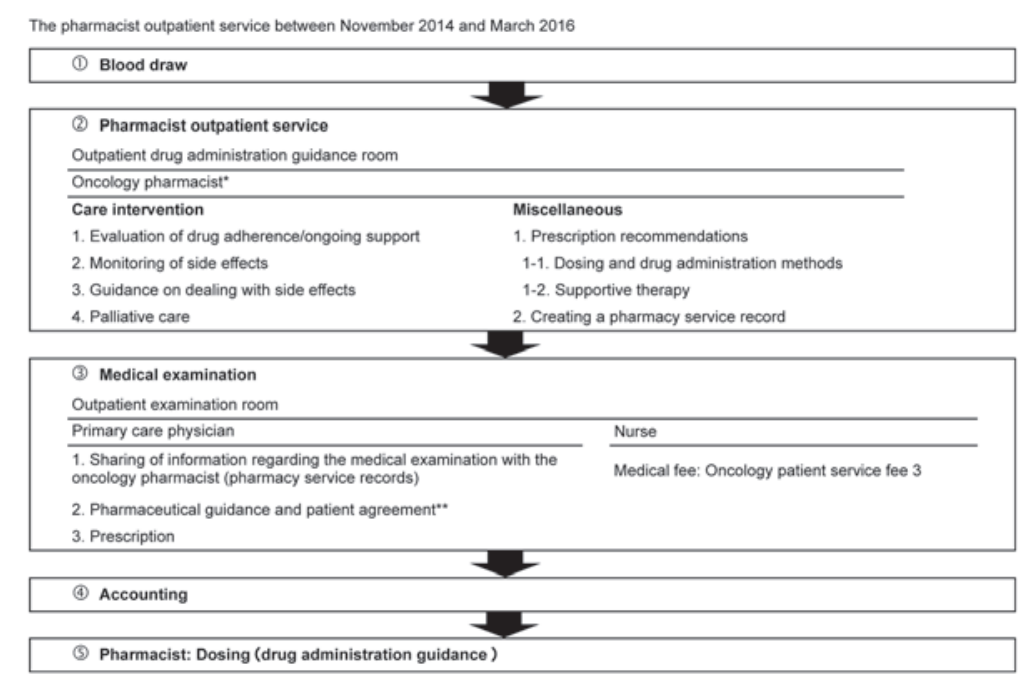

Figure 1. Flowchart of pharmacy outpatient service. Outpatient pharmacy consultations were conducted prior to every medical examination. The pharmacist outpatient service operated on weekdays during the h of 08:15-17:15 between November 2014 and March 2016. "Japanese Society of Pharmaceutical Health Care and Sciences certified oncology pharmacist. ${ }^{* *}$ The patient expressed his/her agreement with the guidance provided by the pharmacist.

of prescription recommendations for supportive care included nutritional supplements, anti-diarrheal, stomatitis remedies and anti-emetics. Telephone consultations regarding skin disorders and diarrhea were performed in 44 cases. The prescription proposal acceptance rate was $92.5 \%$ (198/214 cases).
Persistence rate and reasons for discontinuation of $S-1$ adjuvant chemotherapy. The persistence rate of S-1 adjuvant chemotherapy over the course of a year and the reasons for discontinuation are presented in Table III. The persistence rate of $\mathrm{S}-1$ adjuvant chemotherapy in the PG was significantly 
Table II. Interventions and prescription recommendation details.

A, Intervention performance

\begin{tabular}{lc}
\hline Factor & Value \\
\hline Number of intervention cases & 40 \\
Number of consultations $^{\text {Number of prescription recommendations }}{ }^{\mathrm{a}}$ & 644 \\
Number of cases reflected by these recommendations $^{\mathrm{b}}$ & 214 \\
Prescription recommendation adoption percentage & 92.5 \\
\hline
\end{tabular}

$\mathrm{B}$, Prescription recommendation details

\begin{tabular}{lr} 
Factor & $\mathrm{n}$ \\
\hline Prescription dose & 62 \\
Administration interval (rest days) & 15 \\
Supportive therapy & 132 \\
Others & 5 \\
\hline
\end{tabular}

${ }^{a}$ Number of times that the prescription was proposed to the doctor. ${ }^{b}$ Number of prescriptions proposed by the pharmacist that were accepted by the doctor.

Table III. Persistence rate of S-1 adjuvant chemotherapy over the course of a year.

\begin{tabular}{lccc}
\hline & \multicolumn{2}{c}{$\mathrm{n}(\%)$} & \\
\cline { 2 - 3 } Type & $\mathrm{CG}(\mathrm{n}=94)$ & $\mathrm{PG}(\mathrm{n}=40)$ & P-value \\
\hline Complete $^{\mathrm{a}}$ & $37(39.4)$ & $33(82.5)$ & $<0.0001^{\mathrm{b}}$ \\
Recurrence & $24(25.5)$ & $4(10.0)$ & $0.0322^{\mathrm{b}}$ \\
Adverse events & $30(31.9)$ & $3(7.5)$ & $0.0015^{\mathrm{b}}$ \\
Others & $3(3.2)$ & $0(0.0)$ & 0.3418 \\
Complete/(complete & $37 / 67(55.2)$ & $33 / 36(91.7)$ & $<0.0001^{\mathrm{b}}$ \\
+ adverse events) & & & \\
\hline
\end{tabular}

${ }^{\mathrm{a}}$ The persistence rate of S-1 adjuvant chemotherapy over the course of a year. ${ }^{b} \mathrm{P}<0.05$ is considered statistically significant. CG, control group; PG, pharmacist outpatient clinic group.

higher compared with that in the CG $(\mathrm{P}<0.0001)$. In addition, the rate of discontinuation due to AEs was significantly lower in the $\mathrm{PG}$ compared with the $\mathrm{CG}(\mathrm{P}=0.0015)$. The specific AEs resulting in discontinuation of S-1 adjuvant chemotherapy are listed in Table IV. The most common reasons for AE-associated discontinuations in the CG were malaise, anorexia, diarrhea and myelosuppression. The most common reasons for AE-associated discontinuations in the PG were malaise, myelosuppression, diarrhea and stomatitis.

The pattern of RDIs. In subjects who completed S-1 adjuvant chemotherapy, the RDIs for the CG and PG were
Table IV. Adverse events associated with discontinuations. CG, control group; PG, pharmacist outpatient clinic group.

\begin{tabular}{lcc}
\hline & \multicolumn{2}{c}{ Number of instances } \\
\cline { 2 - 3 } Adverse event & $\mathrm{CG}(\mathrm{n}=30)$ & $\mathrm{PG}(\mathrm{n}=3)$ \\
\hline Malaise & 13 & 1 \\
Anorexia & 8 & 0 \\
Dehydration & 1 & 0 \\
Rash & 3 & 0 \\
Myelosuppression & 5 & 1 \\
Diarrhea & 6 & 1 \\
Lung infection & 1 & 0 \\
Hyperkalemia & 1 & 0 \\
Stomatitis & 1 & 1 \\
Nausea & 2 & 0 \\
Eye disorders & 2 & 0 \\
Fever & 1 & 0 \\
\hline CG, control group; PG, pharmacist outpatient clinic group.
\end{tabular}

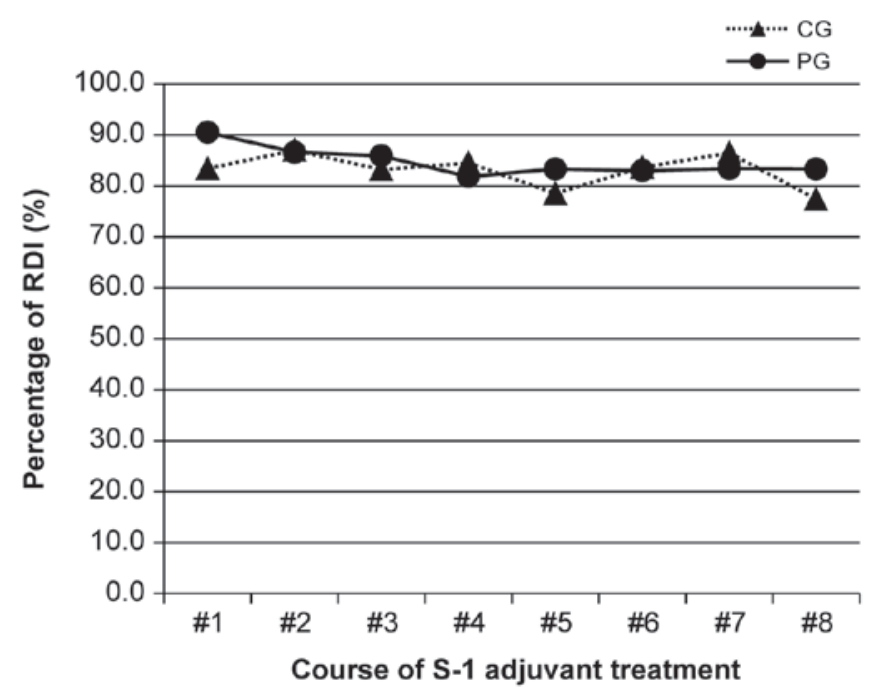

Figure 2. Relative dose intensities between the two groups. In subjects who completed S-1 adjuvant chemotherapy, the RDIs in the CG and PG were 82.9 and $84.7 \%$, respectively $(\mathrm{P}=0.2942)$. RDI, relative dose intensity; $C G$, control group; PG, patient group.

not significantly different at 82.9 and $84.7 \%$, respectively ( $\mathrm{P}=0.2942$; Fig. 2).

Frequency of AEs. The frequencies of AEs in all patients are presented in Table V. There was a significant difference in the incidence of neutropenia, with that in the CG being greater than that in the $\mathrm{PG}(\mathrm{P}=0.0462)$.

The frequencies of AEs in patients who completed the treatment are presented in Table VI. The incidences of leukopenia, neutropenia, aspartate and alanine transaminase increases and total bilirubin increases were greater in the CG compared with the PG $(\mathrm{P}=0.0311,<0.0001,0.0025$ and 0.0219 , 
Table V. Adverse events in all patients who underwent treatment.

\begin{tabular}{|c|c|c|c|c|c|c|c|c|c|c|c|}
\hline \multirow[b]{3}{*}{ Adverse event } & \multicolumn{5}{|c|}{ CG (n=94) } & \multicolumn{5}{|c|}{$\mathrm{PG}(\mathrm{n}=40)$} & \multirow[b]{3}{*}{ P-value } \\
\hline & \multicolumn{4}{|c|}{ Grade } & \multirow{2}{*}{$\begin{array}{c}\text { All } \\
\text { grades }(\%)\end{array}$} & \multicolumn{4}{|c|}{ Grade } & \multirow{2}{*}{$\begin{array}{c}\text { All } \\
\text { grades }(\%)\end{array}$} & \\
\hline & 1 & 2 & 3 & 4 & & 1 & 2 & 3 & 4 & & \\
\hline Leukopenia & 19 & 16 & 6 & 0 & $41(43.6)$ & 11 & 6 & 0 & 0 & $17(42.5)$ & 0.5297 \\
\hline Neutropenia & 14 & 20 & 13 & 0 & $47(50.0)$ & 1 & 10 & 2 & 0 & $13(32.5)$ & $0.0462^{\circ}$ \\
\hline Anemia & 23 & 17 & 1 & 0 & $41(43.6)$ & 6 & 12 & 1 & 0 & $19(47.5)$ & 0.7273 \\
\hline Thrombocytopenia & 4 & 2 & 0 & 0 & $6(6.4)$ & 2 & 1 & 0 & 0 & $3(7.5)$ & 0.7386 \\
\hline AST/ALT increase & 15 & 1 & 0 & 0 & $16(17.0)$ & 4 & 0 & 0 & 0 & $4(10.0)$ & 0.2215 \\
\hline T-Bil increase & 13 & 3 & 0 & 0 & $16(17.0)$ & 5 & 2 & 0 & 0 & $7(17.5)$ & 0.6319 \\
\hline Diarrhea & 22 & 3 & 0 & 0 & $25(26.6)$ & 12 & 1 & 0 & 0 & $13(32.5)$ & 0.8174 \\
\hline Nausea & 14 & 1 & 0 & 0 & $15(16.0)$ & 3 & 2 & 0 & 0 & $5(12.5)$ & 0.4114 \\
\hline Vomiting & 9 & 0 & 0 & 0 & $9(9.6)$ & 2 & 0 & 0 & 0 & $2(5.0)$ & 0.3066 \\
\hline Anorexia & 30 & 6 & 2 & 0 & $38(40.4)$ & 12 & 3 & 0 & 0 & $15(37.5)$ & 0.4529 \\
\hline Stomatitis & 11 & 0 & 0 & 0 & $11(11.7)$ & 10 & 0 & 0 & 0 & $10(25.0)$ & 0.9837 \\
\hline Constipation & 3 & 0 & 0 & 0 & $3(3.2)$ & 3 & 0 & 0 & 0 & $3(7.5)$ & 0.2493 \\
\hline Malaise & 20 & 10 & 1 & 0 & $31(33.0)$ & 10 & 4 & 1 & 0 & $15(37.5)$ & 0.7602 \\
\hline Itching & 5 & 0 & 0 & NA & $5(5.3)$ & 5 & 0 & 0 & NA & $5(12.5)$ & 0.1390 \\
\hline Taste alteration & 5 & 1 & NA & NA & $6(6.4)$ & 5 & 0 & NA & NA & $5(12.5)$ & 0.9321 \\
\hline Hyperkalemia & 9 & 0 & 0 & 0 & $9(9.6)$ & 2 & 0 & 0 & 0 & $2(5.0)$ & 0.3066 \\
\hline Hyperpigmentation & 6 & 0 & NA & NA & $6(6.4)$ & 7 & 0 & NA & NA & $7(17.5)$ & 0.0514 \\
\hline Watering eyes & 10 & 1 & 0 & NA & $11(11.7)$ & 7 & 1 & 0 & NA & $8(20.0)$ & 0.9127 \\
\hline Hand-foot syndrome & 3 & 0 & 0 & 0 & $3(3.2)$ & 4 & 0 & 0 & 0 & $4(10.0)$ & 0.1181 \\
\hline Rash & 10 & 0 & 0 & 0 & $10(10.6)$ & 9 & 0 & 0 & 0 & $9(22.5)$ & 0.9781 \\
\hline Fever & 3 & 0 & 0 & 0 & $3(3.2)$ & 2 & 0 & 0 & 0 & $2(5.0)$ & 0.8429 \\
\hline Others & 16 & 0 & 0 & 0 & $16(17.0)$ & 11 & 0 & 0 & 0 & $11(27.5)$ & 0.9448 \\
\hline
\end{tabular}

andicates statistical significance. CG, control group; PG, pharmacist outpatient clinic group; AST, aspartate transaminase; ALT, alanine transaminase; T-Bil, total bilirubin; NA, not applicable.

respectively). By contrast, the incidences of rash and stomatitis were greater in the $\mathrm{PG}$ compared with the $\mathrm{CG}(\mathrm{P}=0.0271$ and 0.0085 , respectively).

\section{Discussion}

In the present study, continued pharmaceutical intervention resulted in a high persistence rate of S-1 adjuvant chemotherapy over the course of a year and a high completion rate. The increase in persistence and completion rates in the PG may be considered the result of a reduction in discontinuation due to AEs. Prior to intervention, treatment withdrawal due to malaise, anorexia, diarrhea, stomatitis and nausea was observed. However, following intervention, withdrawal due to AEs occurred in only 3 cases. However, in patients who completed S-1 adjuvant treatment, the incidence of rash and stomatitis were greater in the PG compared with the CG. The present study therefore considers that patients in the PG were able to continue S-1 adjuvant treatment with the appropriate therapy support from the pharmacist outpatient service.

In previous studies, in patients who underwent adjuvant chemotherapy following complete tumor resection, patients discontinued adjuvant chemotherapy due to non-hematological toxicities (7). In addition, in a previous case, 1 patient experienced anorexia, fatigue and diarrhea, and decided they no longer wished to undergo S-1 therapy (4). The findings of these previous studies and the present study suggest that patient guidance is paramount for adherence and continuation to S-1 therapy.

In a previous study, the associations between AEs and blood levels of fluorouracil (5-FU) at the time of S-1 administration were evaluated (18). In addition, Van Groeningen et al (19) and Findlay et al (20) reported that the blood levels of 5-FU differed between patients with esophageal and gastric cancer. Patients with gastric cancer who are administered S-1 adjuvant chemotherapy have undergone gastric surgery, and therefore, may have difficulties with food intake, as has been previously reported (3). Therefore, in the present study it was considered that absorption abnormalities may affect the blood concentration of the drug $(3,8)$. In addition, weight loss due to a decrease in postoperative oral intake is likely to reduce muscle mass, which may also affect blood drug levels (21-24). Therefore, the concentration of drug in the blood would exceed the therapeutic index resulting in an increase in AEs, which may lead to subsequent non-adherence. In such cases, dose reductions have the potential to improve adherence. Therefore, in the 
Table VI. Adverse events in patients who completed the treatment.

\begin{tabular}{|c|c|c|c|c|c|c|c|c|c|c|c|}
\hline \multirow[b]{3}{*}{ Adverse events } & \multicolumn{5}{|c|}{$\mathrm{CG}(\mathrm{n}=37)$} & \multicolumn{5}{|c|}{ PG $(n=33)$} & \multirow[b]{3}{*}{ P-value } \\
\hline & \multicolumn{4}{|c|}{ Grade } & \multirow{2}{*}{$\begin{array}{c}\text { All } \\
\text { grades }(\%)\end{array}$} & \multicolumn{4}{|c|}{ Grade } & \multirow{2}{*}{$\begin{array}{c}\text { All } \\
\text { grades }(\%)\end{array}$} & \\
\hline & 1 & 2 & 3 & 4 & & 1 & 2 & 3 & 4 & & \\
\hline Leukopenia & 10 & 13 & 3 & 0 & $26(70.3)$ & 10 & 5 & 0 & 0 & $15(45.5)$ & $0.0311^{\mathrm{a}}$ \\
\hline Neutropenia & 9 & 15 & 7 & 0 & $31(83.8)$ & 1 & 9 & 2 & 0 & $12(36.4)$ & $<0.0001^{\mathrm{a}}$ \\
\hline Anemia & 12 & 11 & 1 & 0 & $24(64.9)$ & 5 & 12 & 1 & 0 & $18(54.5)$ & 0.2626 \\
\hline Thrombocytopenia & 4 & 2 & 0 & 0 & $6(16.2)$ & 2 & 1 & 0 & 0 & $3(9.1)$ & 0.3001 \\
\hline AST/ALT increase & 14 & 1 & 0 & 0 & $15(40.5)$ & 3 & 0 & 0 & 0 & $3(9.1)$ & $0.0025^{\mathrm{a}}$ \\
\hline T-Bil increase & 13 & 3 & 0 & 0 & $16(43.2)$ & 5 & 1 & 0 & 0 & $6(18.2)$ & 0.0219 \\
\hline Diarrhea & 13 & 0 & 0 & 0 & $13(35.1)$ & 8 & 1 & 0 & 0 & $9(27.3)$ & 0.3274 \\
\hline Nausea & 9 & 0 & 0 & 0 & $9(24.3)$ & 2 & 1 & 0 & 0 & $3(9.1)$ & 0.0839 \\
\hline Vomiting & 6 & 0 & 0 & 0 & $6(16.2)$ & 1 & 0 & 0 & 0 & $1(3.0)$ & 0.0726 \\
\hline Anorexia & 12 & 3 & 1 & 0 & $16(43.2)$ & 10 & 3 & 0 & 0 & $13(39.4)$ & 0.4671 \\
\hline Stomatitis & 2 & 0 & 0 & 0 & $2(5.4)$ & 8 & 0 & 0 & 0 & $8(24.2)$ & $0.0271^{\mathrm{a}}$ \\
\hline Constipation & 3 & 0 & 0 & 0 & $3(8.1)$ & 3 & 0 & 0 & 0 & $3(9.1)$ & 0.6066 \\
\hline Malaise & 11 & 4 & 0 & 0 & $15(40.5)$ & 10 & 4 & 1 & 0 & $15(45.5)$ & 0.4312 \\
\hline Itching & 1 & 0 & 0 & NA & $1(2.7)$ & 4 & 0 & 0 & NA & $4(12.1)$ & 0.1447 \\
\hline Taste alteration & 2 & 0 & NA & NA & $2(5.4)$ & 5 & 0 & NA & NA & $5(15.2)$ & 0.1696 \\
\hline Hyperkalemia & 7 & 0 & 0 & 0 & $7(18.9)$ & 2 & 0 & 0 & 0 & $2(6.1)$ & 0.1051 \\
\hline Hyperpigmentation & 4 & 0 & NA & NA & $4(10.8)$ & 7 & 0 & NA & NA & $7(21.2)$ & 0.1938 \\
\hline Watering eyes & 3 & 1 & 0 & NA & $5(10.8)$ & 6 & 1 & 0 & NA & $7(21.2)$ & 0.1938 \\
\hline Hand-foot syndrome & 1 & 0 & 0 & 0 & $1(2.7)$ & 4 & 0 & 0 & 0 & $4(12.1)$ & 0.1447 \\
\hline Rash & 1 & 0 & 0 & 0 & $2(2.7)$ & 8 & 0 & 0 & 0 & $8(24.2)$ & $0.0085^{\mathrm{a}}$ \\
\hline Fever & 2 & 0 & 0 & 0 & $2(5.4)$ & 1 & 0 & 0 & 0 & $1(3.0)$ & 0.5434 \\
\hline Others & 11 & 0 & 0 & 0 & $11(29.7)$ & 11 & 0 & 0 & 0 & $11(33.3)$ & 0.4729 \\
\hline
\end{tabular}

CG, control group; PG, pharmacist outpatient clinic group; AST, aspartate transaminase; ALT, alanine transaminase; T-Bil, total bilirubin; NA, not applicable.

current study, the pharmacist outpatient service was utilized during the initial administration of S-1 to identify any patients requiring dose reductions due to possible eating difficulties or absorption problems.

During chemotherapy with oral anti-cancer drugs, medication adherence is important. Direct associations between adherence in patients undergoing chemotherapy with oral anti-cancer agents and pharmacist-mediated provision of education on correct drug use and the avoidance of AEs have been reported $(6,10)$. In the present study, the total prescription proposal acceptance rate was $92.5 \%$ (198/214 cases). Such a high rate indicates that pharmacists are able to appropriately evaluate the association between medication-related AEs and prescription recommendations. It is necessary to consider symptoms when assessing AEs associated with chemotherapeutic agents; however, a physician may not be able to provide adequate support during complicated outpatient examinations (8). Pharmacists frequently have varying perspectives on the outpatient situation when proposing supportive care and evaluating therapeutic effects and AEs. Pharmacists interview patients about their lifestyle, physical condition and drug intake, obtaining a more holistic understanding of an individual's requirements. In addition, as medication experts, pharmacists have a greater understanding of medication adherence and AEs. Therefore, the present study hypothesizes that a pharmacist may be able to intervene in patient treatment, as they have a different viewpoint to that of the physician.

With regard to the results of the ACTS-GC study, the prognosis was superior in patients who continued S-1 adjuvant chemotherapy for at least 1 year (1). Furthermore, the prognosis was improved when the RDI was $>70 \%$ (1). In the present study, patients who were able to complete $\mathrm{S}-1$ adjuvant chemotherapy following intervention by the pharmacist outpatient service had an RDI of $>70 \%$. Therefore, it is considered that treatment efficacy may be improved by a pharmacist outpatient service.

In the present study, the completion rate prior to intervention by the pharmacist outpatient service was very low (39.4\%). However, continued pharmaceutical intervention (pharmacist outpatient service) resulted in a high persistence rate of S-1 adjuvant chemotherapy over the course of a year $(82.5 \%)$, which was higher than those reported in previous studies, i.e., $64.2 \%$ (3) and $65.8 \%$ (1). These results indicate the efficiency of the pharmacist outpatient service. Until recently, there was no guidance for S-1 treatment in Ogaki Municipal Hospital, and treatment was conducted at the discretion of the treating physician. In addition, efforts to improve the continuity of S-1 
have been conducted in other facilities. Tatematsu et al (25) reported that the persistence rate of S-1 adjuvant chemotherapy over the course of a year improved from $75 \%$ (33/44 cases) to 92.3\% (12/13 cases) during cooperation with out-of-hospital pharmacies. In addition, Kishimoto et al (26) reported that the persistence rate of S-1 adjuvant chemotherapy over the course of a year was $87.5 \%$ (14/16 cases) following liaisons in the clinical pathway. Therefore, the present study considers that $\mathrm{AE}$ monitoring and outpatient counseling were adversely affected in the previous studies that had lower persistence rates due to the lack of a pharmacist outpatient service.

The present study had several limitations, such as the small number of cases and short follow-up time. However, to validate these findings, more cases are currently being accumulated with extended follow-up times.

In conclusion, the continued pharmaceutical intervention for S-1 adjuvant chemotherapy in patients with gastric cancer led to a reduction in AEs. Further, by feeding back information such as the occurrence of AEs to the physician, the persistence rate of S-1 adjuvant chemotherapy over the course of a year was significantly increased.

\section{References}

1. Sakuramoto S, Sasako M, Yamaguchi T, Kinoshita T, Fujii M, Nashimoto A, Furukawa H, Nakajima T, Ohashi Y, Imamura $\mathrm{H}$, et al: Adjuvant chemotherapy for gastric cancer with S-1, an oral fluoropyrimidine. N Engl J Med 357: 1810-1820, 2007.

2. Kimura M, Usami E, Yoshimura T, Yasuda T, Kaneoka Y, Teramachi H, Sugiyama T and Tsuchiya T: Pharmaceutical care for patients undergoing S-1 plus cisplatin therapy for unresectable recurrent gastric cancer. J Pharm Pract 26: 409-414, 2013.

3. Kimura M, Morihata K, Ito D, Iwai M, Okada K, Usami E, Nakao T, Yoshimura T and Yasuda T: Continuous administration and safety of S-1 in adjuvant chemotherapy for gastric cancer. Gan To Kagaku Ryoho 37: 829-834, 2010 (In Japanese).

4. Iwai M, Kimura M, Yoshimura T and Yasuda T: The necessity of adverse effect monitoring in patients using TS-1: A survey of reasons for treatment withdrawal or switching. J Jpn Soc Hosp Pharm 44: 1386-1388, 2008 (In Japanese).

5. Kimura M, Usami E, Iwai M, Nakao T, Yoshimura T, Mori H, Sugiyama T and Teramachi H: Oral anticancer agent medication adherence by outpatients. Oncol Lett 8: 2318-2324, 2014.

6. Kimura M, Nakashima K, Usami E, Iwai M, Nakao T, Yoshimura T, Mori H and Teramachi H: Adherence and awareness of the therapeutic intent of oral anticancer agents in an outpatient setting. Oncol Lett 9: 2341-2346, 2015.

7. Kawabata R, Imamura H, Kishimoto T, Hachino Y, Yasui Y, Fujino M, Fujii C, Fukunaga M, Ohzato $\mathrm{H}$ and Furukawa $\mathrm{H}$ : Examination of factors influencing continuity of S-1 adjuvant chemotherapy for gastric cancer patients. Gan To Kagaku Ryoho 39: 1205-1208, 2012 (In Japanese).

8. Imamura M, Nakura $\mathrm{H}$ and Takemoto C: Evaluation of usefulness of pharmaceutical outpatient clinic for cancer patients. Jpn J Pharm Health Care Sci 36: 85-98, 2010 (In Japanese).

9. Nakashima K, Mano Y, Ohuchi K, Sato D, Iwata K, Higuchi A, Ebara K, Kato Y, Hirosawa I, Tjima M, et al: Role of pharmaceutical outpatient clinic in cancer patients and evaluation. Jpn J Pharm Health Care Sci 38: 599-608, 2012 (In Japanese).

10. Aimono Y, Nemoto M, Sato W, Saito Y, Aoyama Y, Joko F, Maruyama T and Kamoshida T: Examination of the usefulness of the pharmacists' outpatient clinic for treatment with oral molecule-targeting drugs. Gan To Kagaku Ryoho 40: 901-905, 2013 (In Japanese).
11. MacLeod A, Branch A, Cassidy J, McDonald A, Mohammed N and MacDonald L: A nurse-/pharmacy-led capecitabine clinic for colorectal cancer: Results of a prospective audit and retrospective survey of patient experiences. Eur J Oncol Nurs 11: 247-254, 2007.

12. Wong SF, Bounthavong M, Nguyen C, Bechtoldt $\mathrm{K}$ and Hernandez E: Implementation and preliminary outcomes of a comprehensive oral chemotherapy management clinic. Am J Health Syst Pharm 71: 960-965, 2014

13. Simons S, Ringsdorf S, Braun M, Mey UJ, Schwindt PF, Ko YD, Schmidt-Wolf I, Kuhn W and Jaehde U: Enhancing adherence to capecitabine chemotherapy by means of multidisciplinary pharmaceutical care. Support Care Cancer 19: 1009-1018, 2011.

14. Arakawa-Todo M, Yoshizawa T, Zennami K, Nishikawa G, Kato Y, Kobayashi I, Kajikawa K, Yamada Y, Matsuura K, Tsukiyama I, et al: Management of adverse events in patients with metastatic renal cell carcinoma treated with sunitinib and clinical outcomes. Anticancer Res 33: 5043-5050, 2013.

15. Shah NN, Casella E, Capozzi D, McGettigan S, Gangadhar TC, Schuchter L and Myers JS: Improving the safety of oral chemotherapy at an academic medical center. J Oncol Pract 12: e71-e77, 2016.

16. Kimura M, Go M, Iwai M, Usami E, Teramachi $H$ and Yoshimura T: Evaluation of the role and usefulness of a pharmacist outpatient service for patients undergoing monotherapy with oral anti-cancer agents. J Oncol Pharm Pract: Jun 20, 2016 (Epub ahead of print).

17. US Department Of Health And Human Services: Common terminology criteria for adverse events (CTCAE) version 4.0. United States, National Cancer Institute, 2009. (http://www.acrin. org/Portals/0/Administration/Regulatory/CTCAE_4.02_200909-15_QuickReference_5X7.pdf).

18. Matsumoto H,Hirai T, Hirabayashi Y,Murakami H,Higashida M, Kawabe Y, Fuchimoto M, Fujikura H, Hato S, Urakami A, et al: Pharmacokinetics of 5-FU after S-1 oral administration for adjuvant chemotherapy in gastric cancer patients. Gan To Kagaku Ryoho 34: 869-873, 2007 (In Japanese).

19. van Groeningen CJ, Pinedo HM, Heddes J, Kok RM, de Jong AP, Wattel E, Peters GJ and Lankelma J: Pharmacokinetics of 5-fluouracil assessed with a sensitive mass spectrometric method in patient on a dose escalation schedule. Cancer Res 48: 6956-6961, 1988.

20. Findlay MP, Raynaud F, Cunningham D, Iveson A, Collins DJ and Leach MO: Measurement of plasma 5-fluorouracil by high-performance liquid chromatography with comparison of results to tissue drug levels observed using in vivo 19F magnetic resonance spectroscopy in patients on a protracted venous infusion with or without interferon-alpha. Ann Oncol 7: 47-53, 1996.

21. Aslani A, Smith RC, Allen BJ, Pavlakis N and Levi JA: The predictive value of body protein for chemotherapy-induced toxicity. Cancer 88: 796-803, 2000.

22. Gusella M, Toso S, Ferrazzi E, Ferrari M and Padrini R: Relationships between body composition parameters and fluorouracil pharmacokinetics. Br J Clin Pharmacol 54: 131-139, 2002.

23. Prado CM, Baracos VE, McCargar LJ, Mourtzakis M, Mulder KE, Reiman T, Butts CA, Scarfe AG and Sawyer MB: Body composition as an independent determinant of 5-fluorouracil-based chemotherapy toxicity. Clin Cancer Res 13: 3264-3268, 2007.

24. Prado CM, Baracos VE, McCargar LJ, Reiman T, Mourtzakis M, Tonkin K, Mackey JR, Koski S, Pituskin E and Sawyer MB: Sarcopenia as a determinant of chemotherapy toxicity and time to tumor progression in metastatic breast cancer patients receiving capecitabine treatment. Clin Cancer Res 15: 2920-2926, 2009.

25. Tatematsu M, Kuroki R, Hata T, Hata T and Muro K: Outcomes of support for ambulatory cancer patients through a collaborative alliance of doctors, nurses, hospital pharmacists and community pharmacists. Jpn J Pharm Palliat Care Sei 7: 13-19, 2014 (In Japanese).

26. Kishimoto T, Imamura H, Kawabata R, Kimura Y, Fukunaga M and Ohzato H: Feasibility and outcome of S-1 adjuvant chemotherapy for patients with gastric cancer treated based on the liaison-clinical pathway. Gan To Kagaku Ryoho 40: 489-492, 2013 (In Japanese). 